\title{
ASSOCIATIONS BETWEEN WESTERN AND MEDITERRANEAN- TYPE DIETARY PATTERNS AND ANXIETY AND STRESS
}

\author{
M. Kamali ${ }^{a}$, F. Dastsouz ${ }^{a}$, F. SAdEGHI ${ }^{a}$, S. Amanat ${ }^{a}$ and M. AKhlaGhi ${ }^{b *}$ \\ ${ }^{a}$ School of Nutrition and Food Sciences, Shiraz University of Medical Sciences, Shiraz. Iran \\ ${ }^{\mathrm{b}}$ Nutrition Research Center, School of Nutrition and Food Sciences, Shiraz University of Medical Sciences, Razi \\ Blvd., Shiraz. Iran
}

(Received: 9 November 2015; accepted: 8 December 2015)

\begin{abstract}
In this study we investigated the relationship between dietary patterns and anxiety and stress in adults living in Shiraz, Iran. In a cross-sectional design, 416 subjects (180 men and 236 women) aged 20 to 50 years were selected by stratified multistage random sampling. Dietary intakes were assessed using a semi-quantitative food frequency questionnaire (FFQ). Mental health information was collected by depression, anxiety and stress scale (DASS) questionnaire. Three major dietary patterns were extracted by factor analysis: vegetable, Western, and Mediterraneantype dietary patterns. Regression analysis showed a strong positive association between Western dietary pattern and anxiety ( $\beta=0.66 ; 95 \%$ CI: $0.03,1.28)$, and stress $(\beta=0.84 ; 95 \%$ CI: $0.1,1.57)$. Also, there was an inverse association between Mediterranean-type dietary pattern and anxiety ( $\beta=-0.81 ; 95 \%$ CI: $-1.43,-0.19)$. These associations remained statistically significant even after adjustments for demographic characteristics, physical activity, smoking, body mass index, and energy intake. No association was found between vegetable dietary pattern and any of the assessed psychiatric disorders.
\end{abstract}

Keywords: dietary pattern, anxiety, stress

Mental health disorders are a growing global public health problem. According to recent statistics, approximately one-fifth to half of the world's population experience at least one type of mental disorders during their life (KesSLER et al., 2007). The prevalence of psychiatric disorders in Iran was $23.6 \%$ in 2011 , with anxiety disorders being the most common category disorder (SHARIFI et al., 2015).

The effects of psychiatric distress appear over the lifespan of all individuals in different ethnic, racial, cultural, and socioeconomic groups (JACKSON et al., 2004). Epidemiological studies suggest that anxiety can be categorized as a risk factor of cardiovascular diseases, type 2 diabetes, osteoporosis, decreased cognitive function, and even death (Sсотт et al., 2007). Stress is also a growing public health problem in today's modern life and may directly affect the processes that leads to deterioration of psychological (e.g., depression) and metabolic diseases (McEwEN, 2004). Although pharmacological interventions and psychotherapy are usual strategies for the treatment of psychiatric disorders, recent notions pose lifestyle modifications including dietary modifications and exercise for mental health promotion and effective prevention of mental distress (SARRIS et al., 2012).

Iran is among the countries of the Middle East, with a diet typically like Middle-Eastern dietary pattern (EsMAILZADEH \& AZADBAKHT, 2008). The traditional diet of these countries has its own unique characteristics: large portion sizes, wheat-based (white rice and bread), with a variety of relatively unrefined and hydrogenated fats, and a greater percentage of energy

* To whom correspondence should be addressed.
Phone: +98 71 37251001-4; fax: +98 71 37257288; e-mail: msm.akhlagi@gmail.com

0139-3006/\$ 20.00 C 2016 Akadémiai Kiadó, Budapest 
from carbohydrates. With these features and due to the nutritional transition in this country (GHASSEMI et al., 2002), dietary pattern approach might give different dietary patterns in this region compared with those from other parts of the world.

The available data on the association of dietary pattern with anxiety and stress are very scarce. For instance, there is no report of the association between a healthy diet and anxiety or stress. In the current study, we investigated the relationship between dietary patterns and anxiety and stress. The results of this study may provide nutritionists, dieticians, physicians, and other health-care professionals with information regarding appropriate dietary advice against such mood disorders.

\section{Materials and methods}

\subsection{Subjects}

This cross-sectional study was conducted on 438 adults aged 20-50 years in Shiraz, Iran. Participants were selected by stratified multistage random sampling from households living in 9 municipal districts of Shiraz. Individuals with a history of major psychiatric disorders (e.g., mania and schizophrenia), those taking antipsychotic medications, pregnant and lactating women, subjects with severe illnesses (e.g., cancer and organ failure), and individuals with special diets, diseases, or medications that affect appetite were not included. Some of the aforementioned inclusion criteria were used, because they are states or conditions that may affect lifestyle or psychological status. An informed written consent was obtained from all participants.

\subsection{Data collection}

Data on demographics, family affluence scale (FAS) (Сно \& KHANG, 2010), physical activity, and smoking were collected by trained interviewers using a questionnaire.

\subsection{Anthropometric measurements}

Weight was measured with minimal clothing to the nearest $0.1 \mathrm{~kg}$ using a digital scale (Glamor BS-801, Hitachi, China) and height was measured to the nearest $0.1 \mathrm{~cm}$ by using a non-stretchable tape fixed on a wall, while the person was standing without shoes with heels, buttocks, and shoulders touching the wall. Body mass index (BMI) was calculated by dividing weight in kilograms by the square of height in meters. Physical activity was assessed by the international physical activity questionnaire (IPAQ) and expressed as metabolic equivalent in minutes per week (MET-min/wk) (AINSwORTH et al., 2000).

\subsection{Dietary assessment}

Dietary patterns were assessed by using a 168-item semi-quantitative food frequency questionnaire (FFQ), which was evaluated for validity and reliability in previous studies (EsFahani et al., 2009). The FFQ consisted of a list of foods with serving sizes commonly consumed by Iranians. Participants were asked to report the frequency of consumption of each food item during the previous year on a daily (e.g., bread), weekly (e.g., rice, meat), or monthly (e.g., fish) basis. Portion sizes were then converted to grams by using household measures (Ghaffarpour et al., 1999). Participants with $>70$ blank items on the FFQ ( $n=1)$ 
and those who reported a total daily energy intake outside of 800-4200 kcal ( $\mathrm{n}=21)$ were excluded (Fung et al., 2002). The final analysis was performed on 416 subjects (180 males and 236 females). Because Iranian food composition tables contain limited number of foods, nutrient composition of consumed foods was determined by Nutritionist IV version 3.5.2. However, for some traditional Iranian foods, such as traditional Iranian bread and kashk (one of the Iranian dairy products), we used the Iranian food composition table.

\subsection{Mental health}

Mental health was assessed using a short version of the self-report depression, anxiety, and stress scale (DASS-21) questionnaire (with seven items per subscale) (LoviBOND \& LoviBOND, 1996), which has been validated for Iranian population (SAHEBI et al., 2005).

\subsection{Statistical analysis}

Data were analysed by SPSS software version 19.0. Dietary patterns were identified using a posteriori method, factor analysis, based on the FFQ. The 168 food items were divided into 34 groups based on similarity of nutrient profiles and culinary usage. In some cases, due to a specific nutrient composition (e.g., egg) or a specific cooking procedure (e.g., fried potato) one food item was selected as a food group. Dietary patterns were obtained by principal component factor analysis with varimax rotation on the 34 food groups. Eigenvalues greater than 1 were retained. The Kaiser-Meyer-Olkin (KMO) and Bartlett's tests showed that the data were suitable for this type of analysis (KMO: 0.70, Bartlett: $\mathrm{P}<0.001$ ). The scree plot of eigenvalues indicated that there were three major dietary patterns: vegetable, Western, and Mediterranean-type dietary pattern. Dietary patterns were named based on their ingredients, similarities with common patterns in the world as well as previous studies (SLATTERY, 2010). These three dietary patterns accounted for $9.3 \%, 7.7 \%$, and $7.0 \%$ of the variance in food consumption, respectively, and explained $24 \%$ of the variance distribution. Food groups and their factor loadings are illustrated in Table 1. The Bart factor of dietary pattern was used for the statistical analysis. Higher Bart scores indicated greater and lower Bart scores demonstrated lower diet consumption.

Data were checked for normality using the Kolmogorov-Smirnov test. Multivariate linear regression was used to examine the association between scores of dietary patterns and DASS with adjustments for age, sex, marital status, education, job, family affluence scale, location, and smoking for model 1 and additionally for daily energy intake, BMI, and physical activity for model 2 . 
Table 1. Food groups used in the factor analysis and factor loadings

\begin{tabular}{|c|c|c|c|c|}
\hline \multirow[t]{2}{*}{ Food groups } & \multirow[t]{2}{*}{ Food items } & \multicolumn{3}{|c|}{ Dietary patterns } \\
\hline & & $\begin{array}{l}\text { Vegetable } \\
\text { pattern }\end{array}$ & $\begin{array}{l}\text { Western } \\
\text { pattern }\end{array}$ & $\begin{array}{l}\text { Mediterrane- } \\
\text { an-type } \\
\text { pattern }\end{array}$ \\
\hline Green leafy vegetables & Spinach, lettuce & 0.71 & - & - \\
\hline Yellow vegetables & Carrot & 0.53 & - & - \\
\hline Cabbage & Cabbages & 0.44 & - & - \\
\hline Tomatoes & Tomato, tomato paste & 0.70 & - & - \\
\hline Garlic & Garlic & 0.65 & - & - \\
\hline Other vegetables & $\begin{array}{l}\text { Cucumber, eggplant, onion, green beans } \\
\text { and peas, squash, mushroom, pepper, } \\
\text { corn, turnip }\end{array}$ & 0.72 & - & - \\
\hline Legumes & Lentils, split peas, beans, chick peas, soy & 0.57 & - & - \\
\hline Potatoes & Potatoes & 0.31 & - & - \\
\hline Pickles & Pickles, sauerkraut & - & - & - \\
\hline Processed meats & Sausages & - & 0.57 & - \\
\hline Soda & Soda & - & 0.57 & - \\
\hline Refined grains & $\begin{array}{l}\text { Iranian refined breads, baguette bread, } \\
\text { rice, pasta }\end{array}$ & - & 0.51 & - \\
\hline Salt & Salt & - & 0.46 & - \\
\hline Red meats & Beef, lamb, minced meat, hamburger & - & 0.45 & - \\
\hline Hydrogenated oil & $\begin{array}{l}\text { Hydrogenated oils, grease, butter, } \\
\text { margarine }\end{array}$ & - & 0.38 & - \\
\hline Sugar & $\begin{array}{l}\text { Chocolate, honey, jam, sugar, sugar } \\
\text { cubes, candies }\end{array}$ & - & 0.36 & - \\
\hline Organ meats & Heart, kidney, liver, tongue, brain & - & 0.34 & - \\
\hline Eggs & Eggs & - & 0.31 & - \\
\hline Mayonnaise & Mayonnaise & - & 0.30 & - \\
\hline High-fat dairy & $\begin{array}{l}\text { High-fat milk, high-fat yogurt, cream } \\
\text { cheese, cream, dairy fat, ice cream }\end{array}$ & - & - & - \\
\hline Fried potato & French fries & - & - & - \\
\hline Salty snacks & Biscuits, popcorn, crackers, potato chips & - & - & - \\
\hline Coffee- tea & Tea and coffee & - & - & - \\
\hline Canned fruit & All types of canned fruit & - & - & 0.56 \\
\hline Nuts & $\begin{array}{l}\text { Almond, peanut, walnut, pistachio, } \\
\text { hazelnut, seeds }\end{array}$ & - & - & 0.55 \\
\hline Fruit & All fresh fruit & - & - & 0.52 \\
\hline Fruit juice & All natural juices & - & - & 0.52 \\
\hline Low fat dairy & $\begin{array}{l}\text { Low-fat milk, skim milk, low-fat yogurt, } \\
\text { cheese, Kashk, yogurt drink }\end{array}$ & - & - & 0.42 \\
\hline Fish & All fish types, canned fish & - & - & 0.35 \\
\hline Olive & Olives, olive oil & - & - & 0.34 \\
\hline Poultry & Chicken, turkey, ostrich & - & - & - \\
\hline Sweets & Cookies, cakes, muffins, pies & - & - & - \\
\hline Whole grains & $\begin{array}{l}\text { Iranian whole-wheat breads, barely, } \\
\text { barely bread }\end{array}$ & - & - & - \\
\hline Vegetable oil & All vegetable oils except olive oil & - & - & - \\
\hline Explained variance (\%) & & 9.3 & 7.7 & 7.0 \\
\hline
\end{tabular}

Factors loading lower than \pm 0.30 are not presented for simplicity 


\section{Results and discussion}

Demographic characteristics, lifestyle information, and DASS scores of the study subjects are presented in Table 2.

\begin{tabular}{|c|c|c|c|}
\hline & $\begin{array}{c}\text { Males } \\
\text { Mean (SD) or } \\
n(\%)\end{array}$ & $\begin{array}{c}\text { Females } \\
\text { Mean (SD) or } \\
n(\%)\end{array}$ & $\begin{array}{c}\text { Total } \\
\text { Mean (SD) or } \\
n(\%)\end{array}$ \\
\hline Age (y) & $34.6(9.3)$ & $35.7(8.5)$ & $35.2(8.9)$ \\
\hline Sex, n (\%) & $180(43.3)$ & $236(56.7)$ & $416(100)$ \\
\hline $\begin{array}{l}\text { Marital status, n (\%) } \\
\text { Married }\end{array}$ & $107(59.4)$ & $192(81.4)$ & 299 (71.9) \\
\hline $\begin{array}{l}\text { Education, n (\%) } \\
\text { College }\end{array}$ & $84(46.7)$ & $81(34.3)$ & 165 (39.7) \\
\hline $\begin{array}{l}\text { Job } \\
\text { Employed }\end{array}$ & 147 (81.7) & $197(83.4)$ & $344(82.7)$ \\
\hline $\begin{array}{l}\text { Family affluence scale, n (\%) } \\
\text { Low } \\
\text { Moderate } \\
\text { High }\end{array}$ & $\begin{array}{l}82(45.8) \\
75(41.9) \\
22(12.3)\end{array}$ & $\begin{array}{c}123(52.1) \\
95(40.3) \\
18(7.6)\end{array}$ & $\begin{array}{c}205(49.4) \\
170(41.0) \\
40(9.6)\end{array}$ \\
\hline $\begin{array}{l}\text { Smoking, n (\%) } \\
\text { Smokers }\end{array}$ & $36(20.1)$ & $7(3)$ & $43(10.4)$ \\
\hline $\begin{array}{l}\text { Physical activity, } \mathrm{n}(\%) \\
\text { Low }(<600 \mathrm{Met}-\mathrm{min} / \text { wk }) \\
\text { Moderate }(600-2999 \mathrm{Met}-\mathrm{min} / \text { wk }) \\
\text { High }(\geq 3000 \mathrm{Met}-\mathrm{min} / \text { wk })\end{array}$ & $\begin{array}{c}84(47.2) \\
69(38.8) \\
25(14)\end{array}$ & $\begin{array}{c}161(68.2) \\
63(26.7) \\
12(5.1)\end{array}$ & $\begin{array}{c}245(59.2) \\
132(31.9) \\
37(8.9)\end{array}$ \\
\hline BMI $\left(\mathrm{kg} \mathrm{m}^{-2}\right)$ & $25.9(4)$ & $26.5(4.7)$ & $26.3(4.4)$ \\
\hline Energy intake $\left(\mathrm{kcal} \mathrm{d}^{-1}\right)$ & $2514(680)$ & $2066(571)$ & $2250(646)$ \\
\hline $\begin{array}{l}\text { DASS scores }{ }^{1} \\
\text { Anxiety } \\
\text { Stress }\end{array}$ & $\begin{array}{c}7.2(5.8) \\
12.7(7.8)\end{array}$ & $\begin{array}{l}9.3(6.8) \\
14.6(7.3)\end{array}$ & $\begin{array}{c}8.4(6.5) \\
13.8(7.6)\end{array}$ \\
\hline
\end{tabular}

${ }^{1}$ : DASS scores have a possible range of $0-42$, with higher scores indicating greater anxiety or stress.

Univariate and multivariate linear regression of anxiety, stress, and the three dietary patterns showed no significant association for vegetable dietary pattern (Table 3). But Western dietary pattern was positively associated with anxiety and stress, and contrarily Mediterraneantype dietary pattern was inversely associated with anxiety but not with stress. Adjustments for age, sex, marital status, location, education, family affluence scale, job, smoking, energy intake, physical activity, and BMI did not change the aforementioned associations.

Few studies have investigated the relationship between dietary pattern and stress or anxiety. In a study on adults aged 18-35 years in Tehran a significant positive relationship was found between consumption of processed meats and fast foods with anxiety (BAKHTIYARI et al., 2013). Also, higher consumption of Western dietary pattern and processed foods was associated with increased anxiety in community-dwelling Norwegian adults (JACKA et al., 2011). The current study was the positive association of Western dietary pattern and anxiety as well as an inverse association between a Mediterranean-type dietary pattern and anxiety. 
Table 3. Univariate and multivariate linear regression of dietary patterns and anxiety and stress

\begin{tabular}{llccccc}
\hline & Vegetable pattern & & Western pattern & \multicolumn{3}{c}{$\begin{array}{c}\text { Mediterranean-type } \\
\text { pattern }\end{array}$} \\
& $\beta(95 \%$ CI for $\beta)$ & P value & $\beta(95 \%$ CI for $\beta)$ & P value & $\beta(95 \%$ CI for $\beta)$ & P value \\
\hline Anxiety & & & & & & \\
Unadjusted & $-0.39(-1.02,0.23)$ & 0.22 & $0.66(0.03,1.28)$ & 0.04 & $-0.81(-1.43,-0.19)$ & 0.01 \\
Model 1 & $-0.39(-1.01,0.23)$ & 0.21 & $0.98(0.29,1.67)$ & 0.005 & $-0.58(-1.22,0.06)$ & 0.08 \\
Model 2 & $-0.51(-1.16,0.14)$ & 0.12 & $1.40(0.53,2.26)$ & 0.002 & $-0.94(-1.68,-0.19)$ & 0.01 \\
Stress & & & & & & \\
Unadjusted & $-0.52(-1.25,0.21)$ & 0.16 & $0.84(0.1,1.57)$ & 0.025 & $-0.41(-1.15,0.32)$ & 0.27 \\
Model 1 & $-0.55(-1.29,0.19)$ & 0.15 & $1.28(0.45,2.11)$ & 0.003 & $-0.30(-1.08,0.47)$ & 0.44 \\
Model 2 & $-0.72(-1.50,0.07)$ & 0.07 & $1.61(0.56,2.65)$ & 0.003 & $-0.73(-1.63,0.17)$ & 0.11 \\
\hline
\end{tabular}

Model 1 was adjusted for age, sex, marital status, education, job, family affluence scale, location, and smoking. Model 2 was additionally adjusted for energy intake, BMI, and physical activity. CI, confidence interval

There are similarities between our results for the Mediterranean-type pattern with results of other studies. For example, a lower consumption of fruit was associated with higher scores of perceived stress in a cross-sectional study on college students (LiU et al., 2007). Likewise, a traditional healthy dietary pattern characterized by vegetables, fruit, meat, fish, and whole grains was associated with lower odds for anxiety disorders in a cross-sectional study of women aged 20-93 years in Australia (JACKA et al., 2010). Antioxidants and polyphenols in fruit of the Mediterranean-type dietary pattern may be efficacious in prevention of anxiety (BOUAYED, 2010). Olive oil, one of the components of the Mediterranean-type dietary pattern may also contribute to the inverse association of this pattern with psychiatric disorders. Olive oil produces psychoactive lipid oleamide, which induces sleep and modulates serotonin receptor-mediated signalling (PURI et al., 2000).

We did not find a significant association between vegetable dietary pattern and anxiety, but there was a close to significant inverse association between this dietary pattern and stress after adjustments for confounding factors $(\mathrm{P}=0.07)$. Other investigators, however, have found an inverse association between consumption of vegetables and some other psychological states, such as depression. For instance, TSAI and co-workers (2012) reported that vegetables, but not fruit, were protective against depressive syndrome in older Taiwanese people. In clinical trials also, vegan diets have improved mental health (KATCHER et al., 2010) and decreased anxiety (Agarwal et al., 2014). The reason that we did not find an association between vegetable dietary pattern and psychological distress may be the method of cooking vegetables. Frying is a common procedure of cooking vegetables in Shiraz; so a higher consumption of vegetables may result in a higher intake of fats and resulting in weakening of the inverse association between vegetables and mental health disorders.

There are studies with results contrary to the findings of this study. For example in a study on women 20-93 years no association was found between consumption of a Mediterranean-type diet, containing fruit, salads, fish, tofu, beans, nuts, yogurt, and red wine, and anxiety (JACKA et al., 2010). The reason of discrepancy in the results of studies could be the cohort or cross-sectional nature of the studies, difference in the method of assessing psychological disorders, difference in study population (one sex or both, educational level, healthy subjects or patients), the use of principal component analysis for extraction of dietary patterns, difference in statistical methods, and the type of covariates used. 
IIt is not only diet that affects mood and psychological status, but mental condition can also reciprocally influence diet choices. Individuals with mood disorders often have low quality diets containing lower than recommendations of fruit, vegetables, and grains and greater intakes of palatable foods including processed meats and sugar, fat and salty foods (DAVISON \& KAPLAN, 2012). It is suggested that changes in stress influence food choices (Oliver \& WARDLE, 1999). When anxious or stressed, individuals may increase or decrease their food intake, but they may additionally tend towards special kinds of foods. During anxiety or stress, the choice of food changes from normal meal-type foods to high fat, high palatable snacks, which, in the present study, were located in the Western dietary pattern. In rats, consumption of high-fat and high-sugar foods attenuated stress, which was associated with the decrease of serum corticosterone levels (ORTOLANI et al., 2011).

The strengths of this study was the method of sampling, stratified multi-stage random sampling, by which a good representative sample of adults 20-50 years living in Shiraz was selected.

Our study had several limitations. Although many confounding factors were controlled in the analysis, factors such as family history and recent stressful conditions were not controlled. Moreover, with a cross-sectional design we could not conclude whether an unhealthy dietary pattern preceded development of mental health disorders or if mental disorders caused inappropriate and unhealthy dietary choices.

\section{Conclusions}

Our study showed that the diet has an important relationship with mental status in adults aged 20-50 years. The Western dietary pattern has great associations with anxiety and stress, while a Mediterranean-type dietary pattern containing good quantities of fruit, nuts, fish, and olive oil has good inverse relationship with anxiety. Clinical trials are required to examine the preventive effect of the Mediterranean-type diet on mood disorders.

We are thankful to the subjects who kindly participated in this study. We also thank Mr. Mohsen Karamati for his kind help in data analysis. The present article was extracted from the thesis written by Majid Kamali and was financially supported by Shiraz University of Medical Sciences, grants No. 92-6865.

\section{References}

Agarwal, U., Mishra, S., Xu, J., Levin, S., Gonzales, J. \& Barnard, N.D. (2014): A multicenter randomized controlled trial of a nutrition intervention program in a multiethnic adult population in the corporate setting reduces depression and anxiety and improves quality of life: The GEICO study. Am. J. Health Promot., 29, $245-254$.

Ainsworth, B.E., Haskell, W.L., Whitt, M.C., Irwin, M.L., Swartz, A.M., Strath, S.J., Brien, W.L.O., Bassett, D.R., Schmitz, K.H. \& Emplaincourt, P.O. (2000): Compendium of physical activities: An update of activity codes and met intensities. Med. Sci. Sport. Exer., 32, 498-504.

Bakhtiyari, M., Ehrampoush, E., Enayati, N., Joodi, G., Sadr, S., Delpisheh, A., Alihaydari, J. \& Homayounfar, R. (2013): Anxiety as a consequence of modern dietary pattern in adults in Tehran, Iran. Eat. Behav., 14, 107112.

Bouayed, J. (2010): Polyphenols: A potential new strategy for the prevention and treatment of anxiety and depression. Curr. Nutr. Food Sci., 6, 13-18.

Сно, H.-J. \& Khang, Y.-H. (2010): Family affluence scale, other socioeconomic position indicators, and self-rated health among South Korean adolescents: Findings from the Korea youth risk behavior web-based survey (KYRBWS). J. Public Health, 18, 169-178. 
Davison, K.M. \& Kaplan, B.J. (2012): Food intake and blood cholesterol levels of community-based adults with mood disorders. BMC Psychiatry, 12, 10.

Esfahani, F.H., Asghari, G., Mirmiran, P. \& Azizi, F. (2009): Reproducibility and relative validity of food group intake in a food frequency questionnaire developed for the Tehran lipid and glucose study. J. Epidemiol., 20, $150-158$.

EsMAILZADEH, A. \& AzADBAKHT, L. (2008): Major dietary patterns in relation to general obesity and central adiposity among Iranian women. J. Nutr., 138, 358-363.

Fung, T.T., Hu, F.B., Pereira, M.A., Liu, S., Stampfer, M.J., Colditz, G.A. \& Willett, W.C. (2002): Whole-grain intake and the risk of type 2 diabetes: A prospective study in men. Am. J. Clin. Nutr., 76, 535-540.

Ghaffarpour, M., Houshiar-Rad, A. \& Kianfar, H. (Eds) (1999): The manual for household measures, cooking yields factors and edible portion of foods. (in Farsi) Keshavarzi press, Tehran, Iran

Ghassemi, H., Harrison, G. \& Mohammad, K. (2002): An accelerated nutrition transition in Iran. Public Health Nutr., 5, 149-155.

Jacka, F.N., Mykletun, A., Berk, M., Bjelland, I. \& Tell, G.S. (2011): The association between habitual diet quality and the common mental disorders in community-dwelling adults: The Hordaland health study. Psychosom. Med., 73, 483-490.

Jacka, F.N., Pasco, J.A., Mykletun, A., Williams, L.J., Hodge, A.M., O’Reilly, S.L., Nicholson, G.C., Kotowicz, M.A. \& BerK, M. (2010): Association of Western and traditional diets with depression and anxiety in women. Am. J. Psychiatry, 167, 305-311.

Jacrson, J.S., Torres, M., Caldwell, C.H., Neighbors, H.W., Nesse, R.M., Taylor, R.J., Trierweiler, S.J. \& WiLLiams, D.R. (2004): The national survey of American life: A study of racial, ethnic and cultural influences on mental disorders and mental health. Int. J. Method. Psych., 13, 196-207.

Katcher, H. I., Ferdowsian, H.R., Hoover, V.J., COHEN, J.L. \& Barnard, N.D. (2010): A worksite vegan nutrition program is well-accepted and improves health-related quality of life and work productivity. Ann. Nutr. Metab., $56,245-252$.

Kessler, R.C., Angermeyer, M., Anthony, J.C., De Graaf, R., Demyttenaere, K., Gasquet, I., DeGirolamo, G., Gluzman, S., Gureje, O. \& Haro, J.M. (2007): Lifetime prevalence and age-of-onset distributions of mental disorders in the World Health Organization's world mental health survey initiative. World Psychiatry, 6, 168176.

Liu, C., Xie, B., Chou, C.-P., Koprowski, C., Zhou, D., Palmer, P., Sun, P., Guo, Q., Duan, L. \& Sun, X. (2007): Perceived stress, depression and food consumption frequency in the college students of China seven cities. Physiol. Behav., 92, 748-754.

LoviBond, S.H. \& LoviBond, P.F. (1996): Manual for the depression anxiety stress scales. Psychology Foundation of Australia.Sydney. 42 pages.

McEwen, B.S. (2004): Protection and damage from acute and chronic stress: Allostasis and allostatic overload and relevance to the pathophysiology of psychiatric disorders. Ann. NY Acad. Sci., 1032, 1-7.

Oliver, G. \& Wardle, J. (1999): Perceived effects of stress on food choice. Physiol. Behav., 66, 511-515.

Ortolani, D., Oyama, L., Ferrari, E., Melo, L. \& Spadari-Bratfisch, R. (2011): Effects of comfort food on food intake, anxiety-like behavior and the stress response in rats. Physiol. Behav., 103, 487-492.

Puri, B.K., Richardson, A.J., Stoll, A.L., Marangell, L. \& Severus, W.E. (2000): The effects of olive oil on omega-3 fatty acids and mood disorders. Arch. Gen. Psychiat., 57, 715.

Sahebi, A., Asghari, M.J. \& Salari, R. (2005): Validation of depression, anxiety and stress (DASS-21) for Iranian population. Iran. Psychol., 1, 50-60.

Sarris, J., Moylan, S., Camfield, D.A., Pase, M., Mischoulon, D., Berk, M., Jacka, F. \& Schweitzer, I. (2012): Complementary medicine, exercise, meditation, diet, and lifestyle modification for anxiety disorders: A review of current evidence. Evid. Based Compl. Alt., 2012, Article ID 809653, 20 pages.

Scott, K., Bruffaerts, R., Tsang, A., Ormel, J., Alonso, J., Angermeyer, M., Benjet, C., Bromet, E., Girolamo, D. \& GRAAF, D.R. (2007): Depression-anxiety relationships with chronic physical conditions: Results from the World Mental Health Surveys. J. Affect. Disorders, 103, 113-120.

Sharifi, V., Amin-Esmaeili, M., Hajebi, A., Motevalian, A., Radgoodarzi, R., Hefazi, M. \& Rahimi-Movaghar, A. (2015): Twelve-month prevalence and correlates of psychiatric disorders in Iran: The Iranian Mental Health Survey, 2011. Arch. Iran. Med., 18, 76-84.

Slattery, M.L. (2010): Analysis of dietary patterns in epidemiological research. Appl. Physiol. Nutr. Me., 35, 207210.

Tsai, A.C., Chang, T.-L. \& ChI, S.-H. (2012): Frequent consumption of vegetables predicts lower risk of depression in older Taiwanese - results of a prospective population-based study. Public Health Nutr., 15, 1087-1092. 